\title{
On the Political Substitutability between Tariffs and Subsidies ${ }^{\mathrm{a}}$
}

Daniel Brou ${ }^{b}$ and Michele Rutac

JEL-Classification: F13, D72, F55, H25

Keywords: tariffs, subsidies, lobbying, trade agreements

\section{Introduction}

This paper provides a simple model that highlights the political substitutability between import tariffs and production subsidies. ${ }^{1}$ When taxes are distortionary, political pressures by domestic interest groups representing the import competing sector induce the government to set inefficiently high tariffs and subsidies. If the government commits the tariff to a lower level - for instance by signing a binding commitment in a trade agreement - interest groups demand (and in the political equilibrium obtain) a larger production subsidy. This political substitutability between tariffs and subsidies is shown to reduce social welfare.

\section{The Model}

Consider a standard "Protection for Sale" economy (Grossman and Helpman, 1994): a small open economy with two sectors and two factors of production, labor $(l)$ and capital $(k)$. Each agent is endowed with one unit of labor and population is normalized to 1 . The amount of capital in this economy is fixed and owned

a Paper presented at the SSES Annual Meetings in Geneva, August 2009. Disclaimer: The opinions expressed in this paper should be attributed to the authors. They are not meant to represent the positions or opinions of the WTO and its Members and are without prejudice to Members' rights and obligations under the WTO.

b Management and Organizational Studies, The University of Western Ontario, 3215 Social Science Centre, London, ON N6A 5C2, Canada (email: dbrou@uwo.ca).

c Economic Research and Statistics Division, World Trade Organization, Rue de Lausanne 154, 1211 Geneva 21, Switzerland (e-mail: michele.ruta@wto.org).

1 The model presented here is a simplified version of BROU and RUTA (2009). We refer the reader to the latter work for additional results and generalizations. 
by a subset of the population of measure zero. The first sector, which we will refer to as the numeraire sector, produces a non-tradable good the price of which we normalize to one. Production of the numeraire good requires the linear technology $x_{n}=l+k_{n}$, where $k_{n}$ denotes capital specific to the numeraire sector. The manufactured good is produced with the production function $x\left(l, k_{m}\right)=l^{1 / 2} k_{m}^{\beta}$, where $k_{m}$ is the amount of capital specific to the manufacturing sector.

The manufactured good is traded internationally and its international price is denoted with $p^{*}$. The government has at its disposal two policy instruments: an ad valorem tariff $t \geq 0$ and a production subsidy $s \geq 0$. Thus, the domestic price of the manufactured good is $p_{y}=p^{*}(1+t)$, while the net revenue to producers is given by $p_{x}=p^{*}(1+t)+s$. Supply in the manufacturing sector is derived from profit-maximization and is given by $x\left(p_{x}\right)=(1 / 2 w) k_{m}^{2 \beta} p_{x} \equiv f p_{x}$. Profits in the manufacturing sector are given by

$$
\pi\left(p_{x}\right)=\frac{\left(f p_{x}\right)^{2}}{2 f}=\frac{\left[x\left(p_{x}\right)\right]^{2}}{2 f} .
$$

Consumer preferences are quasi-linear and take the form $y_{n}+u(y)$, where $y_{n}$ and $y$ are the quantity consumed of the numeraire and of the manufacturing good, respectively. Utility takes the form $u(y)=1 / e\left[v y-\left(y^{2} / 2\right)\right]$ such that $y\left(p_{y}\right)=v-e y$. Consumer surplus is

$$
S\left(p_{y}\right)=\frac{\left(v-e p_{y}\right)^{2}}{2 e}=\frac{\left[y\left(p_{y}\right)\right]^{2}}{2 e} .
$$

Aggregate welfare consists of factor incomes, tariff revenue, and consumer surplus:

$$
W=1+k_{n}+\pi\left(p_{x}\right)+S\left(p_{y}\right)-\lambda s x+t p^{*}(y-x),
$$

where 1 and $k_{n}$ are, respectively, total labor income and total returns from owning capital in the numeraire sector, $t p^{*}(y-x)$ is tariff revenue and $\lambda s x$ is the cost of financing the subsidy, with $\lambda \geq 1 .{ }^{2}$ As it is well known, in this setting the welfare maximizing policy mix is $\hat{s}=\hat{t}=0$.

2 Notice that if $\lambda>1$ taxation is distortionary and it imposes a deadweight loss on society equal to $(\lambda-1)$ sx. Matschre (2008) estimated this model for the United States and finds that the parameter $\lambda$ is between 1.03 and 1.05 . 


\section{The Political Equilibrium}

Capital owners in the manufacturing sector are organized to lobby the government for favorable policies. Under the assumption of truthful (or compensating) contributions, the tariff and subsidy rates will maximize the joint utility:

$$
\Omega=W(t, s)+a \pi(t, s) .
$$

Notice that the policies determined here define the government's reservation utility in the bargaining game. We can define it with $\hat{W}=W(\hat{t}, \hat{s})=W(0,0)$. Contributions are given by

$$
c(t, s)=\frac{1}{a}[\hat{W}-W(t, s)] .
$$

The first-order condition for the tariff is

$$
\begin{aligned}
t p^{*}(e+f) & =-\lambda s f+a f p_{x} \Rightarrow \\
t p^{*}[e+(1+a) f] & =-(\lambda-a) s f+a f p^{*}
\end{aligned}
$$

and for subsidy

$$
\begin{aligned}
\lambda s & =-(\lambda-1-a) p_{x}-\lambda t p^{*} \Rightarrow \\
(2 \lambda-1-a) s & =-(\lambda-1-a) p^{*}-(\lambda-a) t p^{*}
\end{aligned}
$$

where the last identity follows from the fact that $p_{x}=(1+t) p^{*}+s$. Substituting one into the other and assuming an interior solution ( $s \geq 0$ and $t \geq 0)$, we have

$$
\tilde{s}=\frac{-[(\lambda-1)(e+f)-a e] p^{*}}{(2 \lambda-1-a) e-(\lambda-1)^{2} f}>0
$$

and

$$
\tilde{t}^{*}=\frac{f(\lambda-1) \lambda p^{*}}{(2 \lambda-1-a) e-(\lambda-1)^{2} f}>0 .
$$

Furthermore, the total level of protection provided to the manufacturing sector is given by 


$$
\tilde{p}_{x}=(1+\tilde{t}) p^{*}+\tilde{s}=\frac{e \lambda p^{*}}{(2 \lambda-1-a) e-(\lambda-1)^{2} f}>p^{*}
$$

Notice that the condition for the subsidy to be positive is

$$
\lambda<1+\frac{e a}{(e+f)} \equiv \tilde{\lambda} \geq 1
$$

When $\lambda \geq \tilde{\lambda}$, the subsidy is zero and the tariff is determined solely by the FOC with respect to $t$ :

$$
\tilde{t}^{\circ} p^{*}=\frac{a p^{*} f}{(1-a) f+e}>0
$$

\section{The Political Substitutability between the Tariff and the Subsidy}

Starting from the political equilibrium $(\tilde{t}, \tilde{s})$, consider imposing a tariff ceiling, $\bar{t}$, such that $\overline{t p}^{*}=\tilde{t p}^{*}-\delta$, with $\delta>0$. The subsidy will be determined by condition (6):

$$
(2 \lambda-1-a) s=-(\lambda-1-a) p^{*}-(\lambda-a) \bar{t} p^{*}
$$

which yields

$$
\frac{\partial s}{\partial \bar{t}}=-\frac{\lambda-a}{2 \lambda-1-a}<0
$$

Furthermore, the corresponding change in the total level of protection provided to the manufacturing sector is given by

$$
\frac{\partial p_{x}}{\partial \bar{t}}=\frac{\lambda-1}{2 \lambda-1-a} p^{*}>0
$$

Notice that while the tariff is reduced, the subsidy increases and the producer price falls. Since $\pi^{\prime}\left(p_{x}\right)=x>0$, returns to capital decrease in response to the imposition of a tariff ceiling with no rules on subsidies. Therefore, a trade 
agreement that sets only a tariff ceiling $\bar{t}<\tilde{t}$ results in a less than proportional increase in the subsidy rate and an overall decline in the producer price. Finally, the political substitutability between tariffs and subsidies has a negative effect on aggregate welfare:

$$
\frac{d W}{d \bar{t}}=\frac{\partial W}{\partial \bar{t}}+\frac{\partial W}{\partial s} \frac{\partial s}{\partial \bar{t}}=-\operatorname{axp}^{*}\left[\frac{\lambda-1}{2 \lambda-1-a}\right]<0 .
$$

\section{Concluding Remarks}

Special interests representing import competing producers lobby for protection in the attempt to raise domestic prices (and, hence, profits). When taxes collected to finance subsidies are not distortionary, efficient lobbying implies that in the political equilibrium only production subsidies will be positive and the tariff will be zero (see Grossman and Helpman, 2001, chapter 7). In this case, there is no need to sign a trade agreement that commits the tariff level - and, a fortiori, there is no substitution effect between tariffs and subsidies.

This paper contributes to the literature in two ways. First, it shows that when taxes are distortionary, a combination of positive tariffs and subsidies emerges in the political equilibrium. As the lobbying contributions compensate the government for the loss in social welfare due to the policy distortion, the lobby internalizes the negative effect that taxation has on social welfare. Second, we find that imposing an external constraint on the level of the tariff (for instance through a trade agreement) increases the equilibrium subsidy. Intuitively, the lobby simply substitutes the first policy tool with the latter to achieve protection. As taxation is distortionary, a higher subsidy leads to a social welfare loss.

The results of this model also hint at an interesting extension. The distortionary effects of lobbying may be exacerbated by the fact that they will also affect the allocation of capital across sectors. Though this is not modeled explicitly here, it is plausible to think that the additional profits acquired through lobbying will result in an over-allocation of capital to the protected sector. The role that the international trading system plays in addressing this problem provides an avenue for further research. ${ }^{3}$ 


\section{References}

Brou, Daniel, and Michele Ruta (2009), "A Commitment Theory of Subsidy Agreements", mimeo, WTO.

Grossman, Gene M., and Elhanan Helpman (1994), "Protection for Sale", American Economic Review, 84 (4), pp. 833-850.

Grossman, Gene M., and Elhanan Helpman (2001), Special Interest Politics, MIT Press, Cambridge.

Matschie, X. (2008), "Costly Revenue-Raising and the Case for Favoring Import-Competing Industries", Journal of International Economics, 74, pp. 143-157. 